\title{
Ojos de mujer observan el mundo: la escritura de viaje femenina
}

\author{
Maria Elena CASASOLE \\ Università La Sapienza \\ mariaelena.casasole@gmail.com
}

Recibido: 05.06.2013

Aceptado: 20.11.2013

\section{RESUMEN}

Los textos de viaje de las escritoras "nómadas" representan un lugar simbólico de formación de la propia identidad, expresión de la subjetividad femenina que a partir de sus desplazamientos se apropia de un espacio que siempre había pertenecido al hombre. El abandono del ambiente periférico del hogar permite a la mujer medirse con realidades diferentes y adquirir un bagaje cultural que le había sido negado. Al contacto con la diferencia, la mujeres empiezan un proceso de emancipación que determinará el inicio de una tradición literaria femenina, poniendo fin a la posición hegemónica de los hombres.

Palabras clave: Viaje, Identidad, Escritura, Emancipación, Especificidad femenina.

\section{A different look at society: women's travel writing}

\begin{abstract}
Travel books of "nomadic" women writers represent a symbolic circumstance in which their identity takes shape. Expressing their subjectivity, they conquer spaces that had traditionally always belonged to men. Abandoning their homes, peripheral to society, women start confronting themselves with different realities and acquiring cultural knowledge that had been denied to them. Facing the new experiences, women begin a process of emancipation that gives origin to a female literary tradition, ending men's hegemonic position.
\end{abstract}

Key words: Travel, Identity, Writing, Emancipation, Female Specificity.

Hablar de literatura de viaje de mujeres lleva a marcar la diferencia entre especificidad femenina y masculina tanto en la práctica de viaje como en la modalidad de escritura: la primera tradicionalmente relacionada con el inconsciente, la segunda con la racionalidad.

Sin embargo, la búsqueda de una escritura totalmente femenina, a partir de la pertenencia al género, conlleva el riesgo de dar una lectura a priori de los textos de viaje y del pensamiento femenino sin tomar en cuenta las peculiaridades del sujeto. 
La crítica se ha dividido por tanto entre los que niegan las diferencias entre los dos sexos, uniformando su historia del viaje y superando la dicotomía entre masculino/femenino y los que sostienen que:

"se è vero che la letteratura di viaggio traduce in scrittura la tensione fra il fascino dell'ignoto e il peso del noto e del familiare, fra il desidero di fuga e l'impossibilità di dimenticare la propria cultura, è altresì vero che possono esistere modalità femminili $\mathrm{e}$ maschili di percepire noto e ignoto, interno ed esterno" (Frediani, 2007: 101).

Es incuestionable, en todo caso, que se trata de una herencia literaria patrilineal, producto de una tradición masculina.

Desde los albores de la historia del hombre, es el nomadismo que determina el modelo de vida de hombres y mujeres que indistintamente se desplazan por las extensas sabanas en busca de comida y amparo. Después de la invención de la agricultura, del cultivo de productos y de la crianza del ganado, el hombre tiene que elegir entre nomadismo y sedentarismo. Empieza entonces a delinearse la frontera entre dentro y fuera, entre oikos y distanciamiento, entre fijeza y movilidad. El espacio y el tiempo del hombre y de la mujer se ven separados y contrapuestos: el interno, la casa, se identifica con el femenino; el externo con el masculino, esferas respectivamente de la restricción y de la libertad, de la protección del hombre y de la estabilidad de las mujeres. Se habla, pues, de "identificazione sessuale dello spazio" (Leed, 1992: 143).

Ya en la Epopeya de Gilgamesh la madre del rey sufre y no consigue entender por qué el hijo decide marcharse. Una elección inconcebible para mujeres maternas que son fieles ángeles del hogar, modelos de amor que en casa adquieren su identidad social.

Son los hombres los que se van de viaje, los héroes que ya desde la épica antigua se enfrentan a expediciones y empresas duras, durante las cuales el cansancio y el sufrimiento dominan sus ánimos, guiados por divinidades que les ayudan a superar los obstáculos. En tierra extranjera o de vuelta a la patria, es tarea de las mujeres recibirles, verdaderas mediadoras de la acogida, que hacen más fácil el acceso a lugares desconocidos, convirtiéndose la vuelta en el momento solemne del reconocimiento de sí, de definición de la propia identidad.

"La caratterizzazione maschile del movimento e quella femminile della stanzialità è chiaramente un prodotto di quell'imposizione di modelli culturali che possiamo vedere nel potere che l'immagine del viaggiatore ha esercitato sugli uomini giovani che imitavano e ricercavano il padre idealizzato e assente" (Leed, 1992: 326-327).

La única forma de viaje concedida a las mujeres es el pase real y simbólico de la casa paterna a la del esposo en ocasión del casamiento. Ejemplar es el viaje de 
Andrómaca que, escoltada por Héctor y por sus compañeros, llega a Tebas de Ilión, patria del amado. El recorrido para la mujer que sale de su espacio doméstico está pre-delineado y no prevé la llegada a lugares abiertos, sino a otra casa, la del marido: un desplazamiento único y definitivo que la lleva de nuevo a una condición de fijeza, contrapuesta a la figura en movimiento del esposo, que por otro lado permite la adquisición de una nueva identidad.

La relectura de los mitos da inicio a la interpretación de figuras y símbolos que encubre una pluralidad de significados y asumen, a través de las épocas, imágenes culturales diferentes, volviéndose espacios de frontera entre realidad e imaginación. Las principales figuras femeninas del mundo clásico simbolizan un modelo arquetípico tomado como punto de referencia incluso en los modelos literarios contemporáneos. Así, Penélope es la mujer por excelencia del oikos, símbolo de inmovilidad, donde el único tiempo de acción está dictado por la tejedura de la tela, lo demás es un tiempo de espera que dura veinte años. Una figura, la de la esposa fiel, que encaja plenamente con la ideología patriarcal, contrapuesta a Helena, icono del "eterno femenino". Protagonista de varios mitos de seducción, la bella heroína griega es considerada la causa de daños y destrucciones que llevan a la guerra de Troya, arquetipo de las mujeres infieles al ser raptada por Paris y revindicada por el marido Menelao. A lado de la variante más conocida del mito descrita por Homero, existe otra versión, la de Eurípides, según la cual Helena es ejemplo de devoción conyugal: después del estallido de la guerra se habría escondido en Egipto a la espera de reunirse con su marido Menelao.

Durante la Antigüedad la mujer queda a la espera de un hombre ocupado en conquistas y exploraciones.

Los viajeros de la historia y de la literatura no tienen análogos femeninos $\mathrm{y}$, cuando existen, se trata de mujeres maléficas o infieles que traicionan los valores de la familia y están animadas por impulsos irracionales y por la pasión que hace sus acciones imprevisibles y destructivas. En otros casos, en cambio, los equivalentes femeninos tienen menor importancia con respecto a los masculinos y se mueven en los espacios de la marginalidad social.

"La letteratura confina le figure femminili nei ruoli che i codici patriarcali hanno loro assegnato: a fare da contraltare a Edipo, Ulisse, Amleto, Don Giovanni, Faust troviamo Antigone, Penelope, Ofelia, Donna Elvira, Margherita. Tali figure incarnano il passivo, l'obbedienza, la subalternità, la dipendenza, il nido, il privato: sono oggetti del pensiero, dello sguardo e del desiderio altrui" (Frediani, 2007: 15).

Se trata de una literatura y de una experiencia de carácter masculino, sujeta a una sociedad patriarcal en la cual los desplazamientos de las mujeres son en la mayoría de 
los casos viajes con séquito, de buenas esposas que acompañan al marido, que recrean el ambiente doméstico en tierras lejanas reconfirmando su situación estática. Un estatus que pierden cuando, prisioneras de guerra o fugitivas por amor, deciden romper los vínculos y se ponen en camino en busca de salvación que pueda redimirlas de su condición de mujeres "enjauladas".

Desafortunadamente falta un corpus literario de referencia; sin embargo, de los fragmentos recibidos sabemos que son "viajeras" durante el bajo Medioevo mujeres infelizmente conyugadas, cuya salida representa una ruptura y la imposibilidad de recuperar el pasado. Las mujeres lejos de su casa pierden su identidad también y la condición de personas honestas: adquieren la mala fama de seres transgresores y se vuelven objeto de agresiones sexuales. Las huidas de lugares de segregación, de la propia casa o de un monasterio, representan una traición de las normas morales y de las convenciones sociales, una infracción de los pactos incluso a nivel jurídico, que pone la mujer en la vía del no retorno.

Por lo tanto, huir no es ir más allá de las fronteras geográficas por curiosidad o conocimiento, es deseo de autonomía, es esperanza de satisfacer las propias necesidades en otro lugar. No se registran, ni por escrito ni en los recuerdos, el paisaje y la naturaleza visitados, ni se prefijan metas o itinerarios y a menudo el viaje acaba en un vagar infinito por burdeles sin un verdadero cambio en la existencia.

La Tierra Santa representa uno de los primeros destinos de las viajeras del siglo XI.

Su presencia, como acompañantes de los soldados a la primera cruzada, no siempre es bien vista: sufren violencias, están expuestas a riesgos y viven en condición de esclavitud. Los desplazamientos las conducen hacia una tierra de frontera entre deseo y prohibición, entre lo que está permitido y lo que está vetado. Sus cuerpos inducen a los hombres al pecado, unos cuerpos que la iglesia juzga como efímero, como obstáculo para la salvación del alma.

Existen también las peregrinas que en la Europa medieval pueblan las calles que las llevan hacia los Santos Lugares. Biblia en mano y fe en el corazón, se convierten en las protagonistas del viaje religioso, que empieza en el 326 cuando la emperatriz Elena, madre de Constantino el Grande, se dirige a Palestina en busca de la Vera Cruz, el patíbulo donde murió Jesús, haciendo del mito la realidad. Las ciudades de Jerusalén, Roma y Santiago de Compostela se atestan de pobres fieles o aristocráticos, mujeres y hombres.

Las peregrinas cristianas en Tierra Santa necesitan de un "salvoconducto" para moverse en libertad dentro de las fronteras del Imperio, un permiso de tránsito 
destinado a los hombres de Estado, pero que en algún caso se concede también a mujeres pertenecientes a la aristocracia o a religiosas de rango. El mismo documento se otorga a una monja española, Sor Egeria, que, animada por una profunda religiosidad, se embarca de Galicia a Oriente en un viaje que durará tres largos años, entre 381 y 384 . A pesar de las escasas noticias biográficas, no es difícil intuir que es una mujer fuera de lo común, que se distingue por su coraje y su independencia, por su saber, por la sed de conocer, rasgos que la llevan a seguir los pasos hacia lugares bíblicos. Sus impresiones van a confluir en Itinerarium Egeriae, un manuscrito hallado a finales del Ochocientos falto del principio y de la parte final, en el cual cuenta de forma detallada el viaje a través de la red viaria de las legiones romanas, una peregrinatio que tiene como meta no sólo Jerusalén y los lugares del Antiguo y Nuevo Testamento ya batidos por Santa Elena, sino las ciudades de los Apóstoles y los santuarios de los mártires también. Su obra, donde es observadora y protagonista a la vez de la historia narrada, representa la primera escritura de viaje pensada enteramente en femenino.

Después de Sor Egeria muchas mujeres deciden irse de viaje. Margery Kempe, por ejemplo, visita los principales lugares sagrados de la cristiandad asumiendo el papel de una peregrina aventurera. Mujer y madre de trece hijos, decide marcharse tras una visión que la exhorta a abandonar las vanidades del mundo, consiguiendo que su unión con el marido sea casta y empieza a vivir una vida de devoción a Dios. El relato de sus viajes constituye una parte relevante de su libro, The book of Margery Kempe (1436 aproximadamente), obra considerada la primera autobiografía en inglés.

Las peregrinas parten con conocimiento previo de los lugares a visitar, con textos informativos que durante la época romana gozan de gran éxito entre los eruditos.

Existen dos tipos de "guías" en la Antigüedad: los Itineraria adnotata, que abordan las redes de carreteras desde el punto de salida hasta el final con las distancias correspondientes y los Itineraria picta que incluyen mapas con la imagen de la red vial, de los lugares de descanso y de las características relevantes del paisaje. Los que se dirigen a la Ciudad Eterna en cambio no viajan sin la Mirabilia Romae, una verdadera "guía de viaje" que apareció en el siglo XII y que siguió imprimiéndose en las épocas sucesivas incluso traducidas a varios idiomas, obra de gramáticos y eruditos que recogen tradiciones e indicaciones sobre los monumentos paganos y cristianos de Roma.

El peregrinaje se convierte en el único viaje permitido a las mujeres, una huida de las constricciones familiares y sociales, un iter espiritual capaz no sólo de transformar su personalidad, sino también de trazar un recorrido para llevarlas a la emancipación. 
Ahora los viajes sitúan a la mujer en una posición diferente en la comparación/choque con la alteridad e implican su alejamiento de la inmovilidad.

Durante los siglos XV y XVI empieza a delinearse el perfil de viajeras intrépidas y aventureras que, a pesar de que a menudo permanezcan en el anonimato, han contribuido a escribir la historia del viaje que ha llegado hasta nuestros días.

Nadie recuerda, por ejemplo, a Isabel Barreto, navegadora del siglo XVI, primera mujer almirante de la historia española que decide acompañar al marido, Álvaro de Mendaña, en su segundo viaje hacia las islas Salomón. Una travesía dura, una verdadera aventura marítima durante la cual pierde a su amado; sin embargo, después de tres meses, consigue arribar a las costas de Manila como comandante del barco. Isabel es una entre las veinte mil mujeres, sobre todo andaluzas y extremeñas, que participan en el descubrimiento del Nuevo Mundo: viajan solas o se reúnen con el marido o son viudas que se encargan de alguna hacienda heredada. Unas se vuelven terratenientes, encomenderas o incluso gobernadoras, otras participan en la lucha a lado de los solados más valientes.

Las aventuras vividas por estas exploradoras son objeto de conversación en las tertulias de los salones literarios, nacidas en España durante el Siglo de Oro, el único espacio donde mujeres inquietas y curiosas pueden contar con toda libertad sus experiencias, confrontarse y discutir de política, sexo, cultura y viajes. Un espacio que les permite apropiarse de un lenguaje y de una voz pública para exponer sus historias, sustentando al mismo tiempo la educación y la emancipación femenina y reforzar su posición ideológica en el orden social, desafiando las profundas estructuras patriarcales.

Una posición que la literatura de viaje contribuye a consolidar desde finales del siglo XVIII, favoreciendo la educación de las mujeres a través de la función pedagógica y cognitiva del viaje y de la escritura. De hecho, el intento pedagógico de la narrativa de viaje, además de transmitir conocimiento, da informaciones que las mujeres tienen que utilizar para emanciparse.

Estamos en la época del Grand Tour, rito exclusivamente masculino que deja las mujeres al margen de la historia. Es opinión común y compartida que no existió uno femenino: la experiencia concierne a jóvenes aristocráticos varones que se marchan para una suerte de viaje iniciático en el cual, a través del conocimiento directo lingüístico y cultural, emprenden un camino de formación y de instrucción a la vez, una fase de perfeccionamiento del futuro caballero diplomático y burócrata.

El viaje cultural no pertenece al género femenino; se concede sólo a mujeres acomodadas que se desplazan junto con el marido, recreando incluso en tierra 
extranjera el mismo ambiente familiar que tienen en su patria; siguen por tanto dedicándose al cuidado de la casa y de los hijos. Sin embargo, la posibilidad de observar una nueva realidad, de marcharse, aunque sólo como damas de compañía, abre nuevos horizontes para las mujeres, que hasta ese momento eran meras espectadoras pasivas de los viajes de los demás.

Los exiguos textos de la literatura apodémica femenina permiten acercarse a su manera de pensar, de juzgar los eventos políticos de otros países, la sociedad y los pueblos o de entender su propio sentido del viaje. Se trata en la mayoría de los casos de novelas de género epistolar. Recordamos las cartas de la condesa D'Aulnoy publicadas a final del Seiscientos, Mémoires de la cour d'Espagne, Relation du voyage d'Espagne, que representan la principal fuente de información sobre los hábitos españoles de aquella época. Aunque se dude de su estancia en España, relaborada probablemente a partir de los testimonios de otros viajeros, consigue representar minuciosamente la crisis política y los ambientes cortesanos y ofrece descripciones paisajísticas e informaciones históricas detalladas, añadiendo frecuentes exageraciones y distorsiones de la realidad que dan por otro lado mayor color y viveza a su relato.

Igualmente las Lettres sur l'Angleterre, la Holande e l'Italie (1762) de Madame du Boccage o también el relato de viaje a través de Francia, Alemania y Rusia en 17851786 de Lady Elizabeth Craven y el de la Princesse de Gonzague, Elisabetta Rangoni, escrito para sus amigos durante los recorridos por Italia, Francia y Alemania.

Parece el modelo epistolar única expresión de la especificidad femenina: "in altre parole, il soggetto, per ovvie ragioni interne, determina la forma e il contenuto" (Corsi, 2006: 179), en los cuales la mujer parece plasmar temáticas consideradas típicamente femeninas.

"Laddove a scrivere è una donna viaggiatrice, ci si aspetta certi contenuti, e se questi effettivamente vi si trovano, sembrano la controprova inconfutabile di questo assunto metodologico: la vita quotidiana, il modo di vesitirsi e di allestire la propria casa, la posizione sociale della donna, la relazione tra i sessi, l'educazione dei figli, l'alimentazione, le condizioni sanitarie sono, anzi devono essere, tematiche femminili" (Corsi, 2006: 180).

La literatura de viaje de la Europa pre-revolucionaria no parece diferenciarse en los contenidos específicos, sino por el diferente estatus social de las mujeres viajeras. La mayoría de las veces están sujetas a una trabazón familiar, en un contexto de grupo donde su función es sólo de compañía, sin provocar rupturas ni "arranques de genio". Si por un lado el "viaje en grupo" mantiene inalterada la condición de la mujer 
siempre vinculada al núcleo familiar, por otro determina una apertura significativa de los horizontes mentales y geográficos.

En el siglo XVIII muchas mujeres empiezan a soñar con desplazarse más allá de las elegantes rutas del Grand Tour y giran la mirada hacia el Este.

Oriente representa un lugar para la confrontación y la reflexión sobre la propia condición de mujer, permitiendo ese "nomadismo dello sguardo" (Frediani, 2007: 4) que las lleva a superar la dialéctica estatismo-movilidad, interno-externo.

El viaje a Oriente tiene sus raíces en el modelo de la antigüedad, el del peregrinaje, aunque ya no sea la motivación religiosa que cautiva a los viajeros. El fascinante Islam aparece a los ojos del utilitarista e imperialista Occidente como un lugar de magia y encanto, un lugar quimérico donde refugiarse en busca de un exotismo romántico, donde abandonarse a ese clima de espiritualidad propio de la tierra del Sol.

Del Este llegan las Turkish Embassy Letters (1762) de la escritora inglesa Lady Mary Wortley Montagu, considerada la pionera de la literatura de viaje femenina en Oriente, que relatan la historia de su viaje a Turquía a lado del marido nombrado embajador. Las cartas serán modelo de inspiración para las escritoras/viajeras sucesivas. Nos ofrecen la lectura de un mundo femenino turco a través de los ojos de una dama de corte inglesa del Setecientos, que abre las puertas al Orientalismo y que permite a su espíritu libre dejar a sus espaldas una sociedad cerrada y concederse una posibilidad de regeneración. Si bien no subvierte el modelo estereotipado de la mujer viajera con el séquito, Lady Mary va más allá de su papel de mujer y madre y se pone como observadora del mundo visitado, deleitada y vivaz, asumiendo como propias las tradiciones extrañas. Logra penetrar en la realidad que la rodea, cogiendo los matices y las diferencias, sin ponerse en una posición de superioridad, sino superando las barreras y abriéndose a un Oriente que ya no es lejano y cruel y que puede tocar gracias a la curiosidad nunca invasiva de su ser y a su manera de enfrentarse.

Su atención se centra de modo especial en los espacios exclusivamente femeninos: el harem, propio de las clases sociales acomodadas, es el espacio doméstico de las mujeres orientales y el hammam (el baño turco), el único lugar de accesibilidad social para las mujeres. Espacios privilegiados por lo tanto de la narración femenina que entran también en la escritura de Cristina Trivulzio di Belgiojoso, aristocrática milanesa que visita Oriente por motivos únicamente políticos y que participa activamente al Resurgimiento italiano, costándole el exilio a Francia. Un viaje empezado en 1849 y terminado en 1855 que la ve recorrer mar y tierra en sentido circular pasando por Grecia, Asia Menor, Constantinopla, Siria, Palestina y Egipto con un viraje hacia el interior turco, la remota y desolada valle de Ciaq Maq Oglù, cerca del actual Ankara. El viaje proporciona material de escritura para el epistolario 
Souvenirs dans l'exile (1850) y para el diario de viaje Asie Mineure et Syrie (1858) que manifiesta los pensamientos de una mujer que, si bien está libre de viajar, sigue sintiéndose atada a su mundo familiar y a su tierra de adopción. Da espacio, además, a descripciones realistas, eliminando todas referencias míticas y criticando el harem como lugar de la brutalidad masculina, mostrando a veces cierto desprecio para las ciudades visitadas, consideradas ahora poco auténticas. Ambas escritoras, Lady Montagu y Belgiojoso, participan del proceso de metamorfosis del viajero real en el personaje del narrador, pase determinante en la profesionalización de la mujer escritora.

También hay mujeres comprometidas con la política como Madame de Stäel, que decide vivir un exilio errante. Después de los exordios de la Revolución Francesa le cautiva el pueblo que coge las riendas del propio destino e intenta derrotar un ancien régime cerrado e injusto. Sin embargo, el autoritarismo de Napoleón la inquieta así como la perspectiva de un imperio. Están vivos en ella el deseo de lucha por la independencia, la libertad del pueblo y la idea de nación-estado. Después de las peregrinaciones por Alemania, descritas en De l'Allemagne (1810), queda fascinada por la cultura alemana y su elogio le cuesta la aversión del gobierno napoleónico y como consecuencia el exilio. Corinne ou de l'Italie (1807), en cambio, está escrito después del viaje a Italia, que le permite entrar en profundo contacto con la cultura del pueblo hasta llegar a asumir las perspectivas del mismo.

A partir del Ochocientos las mujeres alcanzan un nivel de movilidad que las lleva a efectuar grandes viajes en solitario. Es el ambiente puritano y agobiante de la época victoriana inglesa que constituye un trampolín para todas esas mujeres deseosas de romper sus cadenas. No es una casualidad entonces que mujeres inquietas, cultas y fuera de lo común, aparecen justamente en esta época, que deciden marcharse sin renunciar a ser elegantes damas del Imperio británico, aunque en algunos casos están obligadas a disfrazarse para pasar desapercibidas.

"Las viajeras victorianas crecían en un ambiente en el que se les enseñaba que el principal modelo de virtudes del país era la reina Victoria que se dedicaba a su marido, a sus hijos y a su Imperio con la misma entrega. Cuando crecieran se esperaba de ellas, como de las jóvenes de la clase alta, que se quedaran en casa, fueran educadas por institutrices y aprendieran lo que se llevaba en la época: equitación, tenis, natación, dos idiomas, algo de literatura, música y arte, labores, pintura y tocar algún instrumento como el piano. Debían aspirar sobre todo a ser buenas esposas y madres ejemplares" (Morató, 2003: 100-101).

Sin embargo, muchas mujeres no están en sintonía con la rígida sociedad donde están atadas y deciden irse de viaje. Isabella Bird es la primera mujer en formar parte de la Real Sociedad Geográfica en Londres, después de dar tres veces la vuelta al mundo. Mary Kingsley recorre en solitario todo el "continente negro" regresando a su 
patria con una amplia colección de insectos, moluscos, plantas, diferentes especies de reptiles y peces, captando la atención de los periodistas para el insólito viaje, después del cual sigue la redacción de sus primeros libros Travels in West Africa, Congo Français, Corisco and Cameroon (1897) y West African Studies (1899).

Entre las viajeras más puritanas y misteriosas de todas, destaca la austriaca Ida Pfiffer, una perfecta mujer de hogar que a los cuarenta y cinco años decide visitar remotas y peligrosas regiones, dando dos veces la vuelta al mundo. La primera publicación de su extraordinaria travesía, Eine Frau fährt um die Welt (1851), la hace famosa en toda Europa, pero su mirada es diferente: representa una cierta actitud de superioridad que la lleva a criticar todo lo que ve, juzgándolo indecente e incívico respecto a las normas de la aristocracia austriaca.

La exploradora Gerdtrude Bell, la reina de Irak, descubre la magia del desierto en 1909, un espacio de libertad lejano a los convencionalismos sociales ingleses; el mismo desierto donde Hester Stanhope, una excéntrica aristocrática inglesa, vive más de sesenta años, convirtiéndose en una suerte de profetisa entre las comunidades druse de Líbano.

Freya Stark, exploradora y ensayista británica, llamada Dama de la Orden del Imperio Británico, es famosa por sus exploraciones en el desierto árabe en 1927 y aun Alexandra David-Néel emprende una peregrinación mística hasta la capital tibetana, Lhasa, ciudad prohibida a los extranjeros y con la cual establecerá una relación tan fuerte que volverá a los cien años para descubrir el Himalaya y encontrar la iluminación.

Damas fascinadas por Oriente que abandonan sus comodidades para aventurarse en lo ignoto, subvierten los convencionalismos de la sociedad victoriana, confirmando sus ansias de aventura y conocimiento. Mujeres cultas de su tiempo que no se conforman con una vida en la patria, a lado de maridos déspotas e intransigentes y que superan las burlas y las críticas de científicos e intelectuales que las juzgan mujeres excéntricas y extravagantes y ridiculizan sus empresas. La coraza creada les sirve para protegerse de los ataques de un mundo que las critica y las rechaza.

La revolución industrial aporta un cambio significativo a la historia de los viajes de las mujeres: no sólo gracias a la mejora de las condiciones materiales del viaje, sino también al hecho que las mujeres ahora desean moverse, deciden sus destinos y empiezan a escribir sobre sí mismas. Las experiencias femeninas están marcadas por el paso de la acción a la representación.

"Rappresentazione/autorappresentazione che si propone in pubblico e che può fruire, attraverso la scrittura, di vaste platee, che può quindi offrire modelli e modificare 
comportamenti. Non tanto la partenza e neanche il ritorno bensì l'alterità si caratterizza come il valore significante e spendibile del viaggio, tutto giocato sul confronto/scontro con l'altro e sulla ricerca/costruzione della propria identità" (Corsi, 2006: 29).

La comparación con la alteridad muda el alma, devuelve la forma a la historia de la mujer, que reconquista autónomamente la identidad de sí y su devenir se afirma como proceso de formación y de determinación. El viaje impone el abandono de los estereotipos que la ven un ser débil e inseguro, le ofrecen la posibilidad de conocer y por lo tanto cambiar, de aproximarse a la realidad en términos concretos y de emancipación.

El viaje de las mujeres es paralelo al desarrollo de los movimientos feministas del siglo XIX, que las ven en lucha por sus derechos. Desde la Revolución Francesa hasta la Primera Guerra Mundial la cuestión de la mujer se vuelve objeto de debate y de lucha política tanto en Europa como en los Estados Unidos. Se hace estrecho el vínculo entre escritura y rebelión: todo el mundo participa de este clima efervescente encontrando un espacio de reflexión feminista.

Es un tiempo fundamental en la historia de la mujer. Autonomía y movimiento se imponen a su ser: empieza la gran aventura, que la ve no más como mujer o madre, sino como sujeto autónomo en continuo devenir. Viaje y trabajo se dan la mano en esta nueva dimensión femenina: lo que había sido siempre prerrogativa masculina ahora deja el puesto a la mujer que se apropia de espacios hasta ese momento negados, empezando un proceso de emancipación capaz de dar vida a un sujeto nuevo, que adquiere una nueva identidad social e individual.

El primer paso dado hacia la conquista de un espacio diferente respecto al del hogar es el desplazamiento desde la ciudad gracias al trabajo y al desarrollo económico y social: así, de la ciudad al resto del mundo el paso es breve.

El concepto de viaje está en un primer momento fuertemente vinculado al de la emigración: las mujeres que se marchan solas son obreras que van hacia las fábricas, en busca de condiciones laborales más favorables; otras dejan su país con el séquito de la familia quedando todavía en una condición de constricción y dependencia económica. Sin embargo, para ellas el viaje representa una nueva experiencia: es alejamiento de casa, posibilidad de conocer otras jóvenes en su misma condición con las cuales establecer una relación de solidaridad, una posibilidad de confrontarse y de reforzar la pertenencia al género.

Las mujeres se convierten en protagonistas de un destino ya no vinculado al ámbito familiar. La búsqueda de espacios de libertad no ha sido fácil para ellas, el tiempo pasado en la sombra no puede hallar la luz con un simple desplazamiento. El 
pudor y la vergüenza las hacen todavía veladas y con poca credibilidad. Las que se marchan por motivos científicos o por estudio tienen menos éxito que sus colegas hombres, pues las actividades académicas estaban todavía circunscritas al mundo masculino. En algunos casos intentan disfrazarse con el fin de viajar desapercibidas y sin obstáculos.

Sólo con las reivindicaciones femeninas del Novecientos se nota la afirmación de paradigmas literarios alternativos a los tradicionales. "Il mondo che abbiamo ereditato [...] è stato costruito dagli uomini con i loro viaggi; è stato occupato, perpetuato e ha ricevuto sostanza dalle donne" (Leed, 1992: 332).

En el Occidente contemporáneo las mujeres están ahora libres de viajar, solas o en compañía, poniendo fin a la caracterización sexual de la movilidad. De hecho, la aparición de una "conciencia global" ha permitido al mundo entero comunicarse entre sí manifestándose de formas diferentes, que comprenden ámbitos infinitos, desde las nuevas tecnologías hasta los movimientos socio-culturales.

El reciente fenómeno de la globalización ha sido decisivo para la literatura de viaje, que en los últimos años ha tenido un auge sin precedentes y ha consentido abrir las puertas al viaje incluso a grupos sociales hasta hace poco tiempo excluidos, incrementando la frecuencia de los desplazamientos. Estas transformaciones implican una nueva percepción de entender el viaje y consecuentemente de entender el mundo. La transposición de la experiencia en escritura, a través de la imaginación y la memoria, supone hoy no sólo la representación de una determinada sociedad o cultura, sino también un ejercicio de introspección, una autoreflexión que permite construir un nuevo ser personal y social, una identidad basada en la dialéctica sujeto/otro.

El viaje se trasforma por tanto en hecho privado, un "viaje interior" centrado en la vida emocional de la viajera, una suerte de peregrinación romántica donde emerge la sensibilidad del autor y la experiencia personal de la mujer. Se celebra entonces el viaje en solitario y se da importancia a los elementos de crisis personal e ideológica que empujan a la mujer al viaje. Desde la segunda mitad del siglo XX la adquisición de la libertad de movimiento y de expresión de la mujer occidental lleva al rechazo de la tradición discursiva, en boga desde la época colonial, donde la escritura de viaje proveía los elementos para evaluar la posibilidad de control y de acceso a los países, pero dejando al escritor en la invisibilidad, encargado sólo de documentarse lo más posible sobre la sociedad visitada, produciendo textos informativos e objetivos sin alejarse de la concepción ideológica de la época. Hoy, en cambio, las peregrinas se centran en sí mismas y el viaje representa una oportunidad para redefinir o reinventar la propia personalidad. 
Las escritoras están ocupadas en desmontar convenciones y constricciones que siempre han obligado a las mujeres a quedarse en casa a la espera de un hombre que vuelve de un viaje y han impulsado a la transformación del espacio extraño, ese externo de la divagación, en el propio universo. Un espacio que alcanzan a través de la escritura también, símbolo de la conquista de la propia identidad y creatividad, intentando recomponer las fracturas y equilibrar las desigualdades. La adquisición entonces del espacio, público y privado, traducido en el acceso al mundo del saber y del trabajo y, por consecuencia, en la independencia económica, representan el momento en el cual el ambiente cerrado y agobiante del hogar se abandona, a pesar del miedo a lugares extraños e inusuales.

Es la circunstancia en la cual empieza el proceso de creación de la mujer y de la escritura de viaje femenino. La literatura de viaje de las mujeres oscila entre el desplazamiento de sí mismas y la reconstrucción de una nueva personalidad en contacto con la diferencia. Su condición de alteridad hace aún más complejo el movimiento de identidad, pero útil para adquirir más conciencia de sí.

"Scrivere è la soglia tra l'esilio da se stesse e dalla propria cultura e il bisogno di appartenere a se stesse, alla propria società e al nuovo mondo che si incontra [...]. La letteratura di viaggio delle donne diviene espressione di una ricerca di ciò che è stato emarginato e represso nell'ordine sociale, l'esperienza e la soggettività del femminile" (Monticelli, 2002: 6).

Para las mujeres viajeras sigue siendo dificultoso plasmar veracidad en su escritura y así es conflictiva su relación con el saber.

"Al irrumpir en el espacio de lo público establecen una relación entre ese espacio, el conocimiento y la autoridad, y para validar sus discursos se sirven del historicismo, que incluye la referencia a las fuentes consultadas para avalar la información brindada en sus relatos" (Araujo, 2008: 1013).

El resultado es un sujeto de la enunciación que tiene que ganar autoridad para que el texto de la narración adquiera unidad, y el yo del autor, credibilidad. La escritura de la mujer ha sido siempre de tipo "relacional", es decir, vinculada a conceptos a los que hacer referencia: el espacio doméstico y el sujeto masculino. Sin embargo, la fragmentariedad de los relatos de viaje no depende del ser femenino, sino del hecho que en la escritura confluyen varios impulsos, por eso es imposible establecer un modelo discursivo homogéneo y unitario y una relación física y estática entre "verdad, poder y saber" (Araujo, 2008).

Sin embargo, la narrativa de viaje pone en común a hombres y mujeres en las suposiciones fundamentales: la mirada curiosa y creativa que observa todo lo que les rodea según sus cánones culturales, un viaje a través de la memoria que recrea el 
itinerario recorrido para mostrarlo a un público expectante y en busca de aventuras, que les lleven lejos de lo cotidiano o que contribuyan a enriquecer su bagaje cultural.

\section{BIBLIOGRAFÍA}

ARAMBEL-GUIÑAZÚ, M. C. ; MARTÍN, C. M. (2001): Las mujeres toman la palabra. Escritura femenina del siglo XIX. Antología, Tomo II, Madrid, Iberoamericana.

ARAÚJO, N. (2008): Veradad, poder y saber: escritura de viajes femenina. Revista Estudios Femenistas, vol. 16, núm. 3, pp. 1009-1029, Brasil, Universidade Federal de Santa Catarina.

[http://www.redalyc.org/articulo.oa?id=38114361019], 26/02/2013.

BRILLI, ATTILIO (1995): Quando viaggiare era un'arte. Il romanzo del Grand Tour, Bologna, Il Mulino.

CORSI, DINORA, ed. (2006): Altrove. Viaggi di donne dall'antichità al Novecento. Roma, Viella.

FERRÚS ANTÓN, B. (2011): Mujer y literatura de viajes en el siglo XIX: entre España y las Américas, Valencia, Publicacions de la Universitat de València.

FREDIANI, F. (2007): Uscire. La scrittura di viaggio al femminile: dai paradigmi mitici alle immagini orientaliste. Reggio Emilia, Diabasis.

LEED, ERIC J. (1992): La mente del viaggiatore. Dall'Odissea al turismo globale. Bologna, Il Mulino.

MCDOWELL, L. (1999): Gender, identity and place: understanding feminist geographies, Minneapolis, University of Minnesota Press.

MONTICELLI, R. (1/2002): Intertestualità, traduzioni e saperi in transito nella letteratura di viaggio: il caso di Anna Jameson. Linguae \&, pp. 3-14, Università di Bologna, http://www.ledonline.it/linguae/allegati/linguae0102monticelli.pdf], 15/02/2013.

MORATÓ, C. (2003): Viajeras intrépidas y aventureras. Barcelona, Debolsillo.

SALCINES DE DELAS, D. (1995): La literatura de viajes: una encrucijada de textos, Madrid: Servicio de Publicaciones, Universidad Complutense.

SZURMUK, M. (2000): Mujeres en viaje, Buenos Aires, Alfaguara. 